Article

\title{
Preparation of High-Performance Carbon Fiber-Reinforced Epoxy Composites by Compression Resin Transfer Molding
}

\author{
Zeyu Sun ${ }^{1,2}$, Jie Xiao ${ }^{3, *}$, Lei Tao ${ }^{1}$, Yuanping Wei ${ }^{4}$, Shijie Wang ${ }^{1}$, Hui Zhang ${ }^{1,2}$, Shu Zhu ${ }^{1,2}$ \\ and Muhuo $\mathrm{Yu}^{1,2, *}$ \\ 1 State Key Laboratory for Modification of Chemical Fibers and Polymer Materials, Donghua University, \\ Shanghai 201620, China; sunzeyu@dhu.edu.cn (Z.S.); 1179137@mail.dhu.edu.cn (L.T.); \\ sjwangdhu@126.com (S.W.); zhanghui@dhu.edu.cn (H.Z.); zhushu@dhu.edu.cn (S.Z.) \\ 2 Key Laboratory of Shanghai City for Lightweight Composites, Donghua University, Shanghai 201620, China \\ 3 Research Center for Analysis and Measurement, Donghua University, Shanghai 201620, China \\ 4 Shanghai Engineering Research Center of Advanced Automotive Body Manufacturing, Donghua University, \\ Shanghai 200092, China; yuanping.wei@ssdt.com.cn \\ * Correspondence: jiex0616@dhu.edu.cn (J.X.); yumuhuo@dhu.edu.cn (M.Y.); Tel.: +021-67792263 (J.X.)
}

Received: 23 November 2018; Accepted: 18 December 2018; Published: 20 December 2018

\begin{abstract}
To satisfy the light weight requirements of vehicles owing to the aggravation of environmental pollution, carbon-fiber (CF)-reinforced epoxy composites have been chosen as a substitute for traditional metal counterparts. Since the current processing methods such as resin transfer molding (RTM) and compression molding (CM) have many limitations, an integrated and optimal molding method needs to be developed. Herein, we prepared high-performance composites by an optimized molding method, namely compression resin transfer molding (CRTM), which combines the traditional RTM and CM selectively and comprehensively. Differential scanning calorimetry (DSC) and rotational rheometry were performed to optimize the molding parameters of CRTM. In addition, metallurgical microscopy test and mechanical tests were performed to evaluate the applicability of CRTM. The experimental results showed that the composites prepared by CRTM displayed superior mechanical properties than those of the composites prepared by RTM and CM. The composite prepared by CRTM showed up to $42.9 \%, 41.2 \%, 77.3 \%$, and $5.3 \%$ increases in tensile strength, bending strength, interlaminar shear strength, and volume fraction, respectively, of the composites prepared by RTM. Meanwhile, the porosity decreased by $45.2 \%$.
\end{abstract}

Keywords: RTM; CM; CRTM; carbon-fiber reinforced epoxy composite; lightweight

\section{Introduction}

Lightweight automobiles are an effective way to realize energy conservation and emission reduction as vehicle usage increases. Carbon fiber (CF)-reinforced epoxy composites show excellent performances with light-weight, high-specific strength and stiffness, and excellent design-ability are a preferable alternative to replacing the traditional metal counterparts [1-6]. It has been widely used in aerospace, military products, lightweight automobiles, and so on [7-10]. The properties of composites depend on, not only the distribution and content of matrix and reinforcing materials, but also the molding methods. Composites comprising the same matrix and reinforcing materials may exhibit varying performances depending on the molding methods.

The resin transfer molding (RTM) method originated from the cold-casting process in the 1950s. Statistically, the product rate of RTM among developed countries has continued to increase by $10 \%$ in recent years [11]. In just 20 years from 1970 to 1990, the RTM process has become more mature and has 
been generally applied to manufacturing individual parts and even entire bodies [12]. RTM represents a closed-cavity molding technique that offers good dimensional precision and surface quality for the manufactured components. The ease of processing promotes wide applications of RTM in aerospace engineering [5]. As dry fibers are required to be fully impregnated during the injection process, the liquid resin for RTM should have a low viscosity and a wide injection temperature range $[13,14]$. The poor fluidity of epoxy resin seriously restricts its applications, and cracks and defects occur when epoxy-based components are subjected to external forces. Therefore, optimization of the RTM process is imperative in molding CF-reinforced epoxy composites to maintain its excellent performance $[15,16]$. Many studies have reported on the limitations of RTM technology. Feng et al. studied the formation of bubbles in the resin filling stage and proposed that the bubbles form at the end of the transverse fiber bundles [17]. Li et al. investigated the theory of defect formation, which could be used to predict the formation mechanisms of layer defects according to the flow pattern of resin [18]. Furthermore, Qin et al. believed that the ultrasonic treatment contributed to the improved impregnation of fiber reinforcements, thereby improving the mechanical properties of the composites [19].

Unlike RTM, CM (compression molding) is carried out under simultaneous application of heat and pressure. The large-scale heat regulation in CM is conducive to the fluidity of epoxy resin and impregnation of CFs in the mold cavity [20]. While the use of prepregs, which are impregnated with resin and curing agents, brought out problems in storage, transportation, high cost, and further restricted large-scale applications.

To solve the problem of complex molding conditions of RTM and CM in preparing CF-reinforced epoxy composites, some researchers reported compression-resin transfer molding (CRTM), which combined the RTM and CM selectively and optimally for the mass production of CF-reinforced composite automotive parts [21-24]. Bickerton and Kelly introduced the CRTM method computationally and theoretically, and carried out molding and analysis as well as experimental validation of numerical models applied to planar and non-planar geometries [23]. Sreekumar et al. studied the flow and heat transfer during the CRTM method [24]. Apart from the advantages of RTM and CM, the CRTM method enables efficient production and controllable production quality.

Herein, we optimized the molding procedures and parameters of CRTM, and verified its excellent features by comparing it with RTM and CM. Firstly, resin was injected into the closed mold to ensure enough porosity of the fabric, and that the dry CFs were quickly impregnated under vacuum. Secondly, the excess resin was discharged under a low pressure to control the resin content. Thirdly, the pressure was raised to improve the compactness during the gelation stage. To confirm the optimum parameters of CRTM, the control variable method was used to prepare different composite samples by RTM and $\mathrm{CM}$, respectively. Meanwhile optimum parameters of CRTM were obtained by debugging the molding parameters constantly. This study focused on investigating and optimizing the CRTM technology by using a double component epoxy as the reinforced matrix. The experiments showed that the CRTM technology meets the requirements of rapid batching, and therefore, its wide application in the industry is expected.

\section{Materials and Methods}

\subsection{Materials and Characterizations}

Bisphenol A-type epoxy resin (X4302A) and Isophorondiamine $\left(\mathrm{C}_{10} \mathrm{H}_{12} \mathrm{~N}_{2}, \mathrm{X} 4302 \mathrm{~B}\right)$ as an amine curing agent were purchased from Bohui New Material Technology Co. LTD., Guangzhou, China. Plain weave CF cloth (T700-12k, Toray) was purchased from Lishuo Composite Materials Co. LTD., Shanghai, China. Prepreg (Plain weave T700-12k Toray/resin YPH-42T) was purchased from Huazheng Composite Materials Co. LTD., Shanghai, China. The curing agent of YPH-42T resin system was Dicyandiamide $\left(\mathrm{C}_{2} \mathrm{H}_{4} \mathrm{~N}_{4}\right)$. The release agent (19RSS) was purchased from Sino Composite Co. LTD., Shanghai, China. 
Equipment: Dual-component RTM injection equipment (ISOJET EQUIPEMENTS, Corbas, France); XLB-D350 plate vulcanization machine (Dehong Rubber and Plastic Machinery Co. LTD, Shanghai, China).

The rheological properties of the epoxy resin system were performed on the Physica MCR501 rheometer (Anton Paar, Graz, Austria) with 25-mm-diameter parallel plates under a nitrogen environment.

The curing characteristics of resin system was carried out on the Modulated DSC2910 differential scanning calorimeter (TA Instruments, New Castle, DE, USA) equipment. The heating rate was set as $5{ }^{\circ} \mathrm{C} / \mathrm{min}, 10^{\circ} \mathrm{C} / \mathrm{min}, 15^{\circ} \mathrm{C} / \mathrm{min}$ and $20^{\circ} \mathrm{C} / \mathrm{min}$ under nitrogen atmosphere with a flowing rate of $50 \mathrm{~mL} / \mathrm{min}$ to record the curing exotherm of resin system.

The glass transition temperature of resin casting body was carried out on the Modulated DSC2910 differential scanning calorimeter (TA Instruments, New Castle, DE, USA) at the heating rate of $10^{\circ} \mathrm{C} / \mathrm{min}$ under nitrogen atmosphere.

The tensile performance test of the composite samples was performed on the universal testing machine (LABSANS Material Testing Co. LTD, Shenzhen, China) at the stretching velocity of $2 \mathrm{~mm} / \mathrm{min}$ according to ASTM D3039. Five pieces of specimen were tested to get the average value of the result as the tensile strength. The size of the specimen was $250 \times 25 \times 2.5 \mathrm{~mm}^{3}$.

The compressive performance test of the composite samples was performed on the universal testing machine at the loading rate of $1.3 \mathrm{~mm} / \mathrm{min}$ according to ASTM D6641. Five pieces of specimen were tested to get the average value of the result as the compressive strength. The size of specimen was $140 \times 12 \times 4 \mathrm{~mm}^{3}$.

The bending performance test of the composite samples was performed on the universal testing machine at the testing speed of $1.0 \mathrm{~mm} / \mathrm{min}$ according to ASTM D7264. Five pieces of specimen were tested to get the average value of the result as the bending strength. The size of specimen was $155 \times 13 \times 4 \mathrm{~mm}^{3}$.

The interlaminar shear performance test of the composite samples was performed on the universal testing machine at the testing speed of $1.0 \mathrm{~mm} / \mathrm{min}$ according to ASTM D2344. Five pieces of specimen were tested to get the average value of the result as the interlaminar shear strength. The size of specimen was $12 \times 4 \times 2 \mathrm{~mm}^{3}$.

The metallographic microscopy test was performed on the Axiovert 40 MAT microscope (Carl Zeiss AG, Oberkochen, Germany), the prepared composite samples were polished first with sandpaper and then with metallographic sandpaper. The samples were then scanned to observe the interface of the fiber and resin system, and the internal pore size and distribution after a final polish with the instrument.

The fiber volume and porosity tests were performed according to the GB/T 3365-2008 CF-reinforced plastic fiber volume content and porosity test standard.

\subsection{Preparation of Casting Body by Bisphenol A-Type Epoxy Resin System}

The bisphenol A-type epoxy resin was blended with the amine curing agent in a mass ratio of 100:45 and then vacuum degassed for $30 \mathrm{~min}$ at $40{ }^{\circ} \mathrm{C}$. Meanwhile, the mold was preheated in a vacuum oven at $40^{\circ} \mathrm{C}$. After degassing, the resin was injected into the mold slowly and then solidified in the vacuum oven to obtain a resin casting body as shown in Figure 1. 


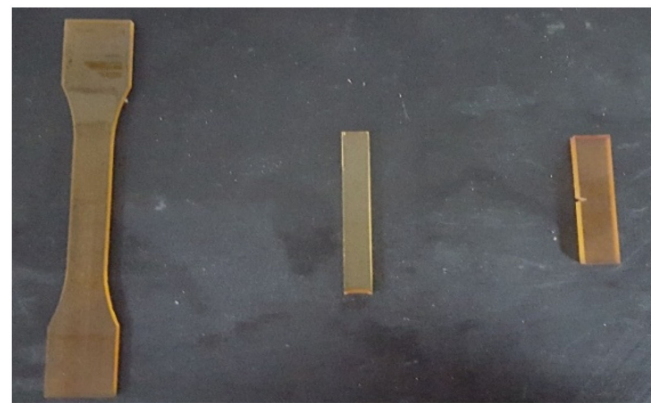

Figure 1. Photo of resin casting body.

\subsection{Preparation of Composite Samples by CM}

Prepreg was used to achieve the optimum processing parameters by the control variable method. By comparing the surface morphology and mechanical properties of the composite samples, the optimum parameters of CM were confirmed. The molding scheme and specimens' photo of CM technology are shown in Scheme 1.
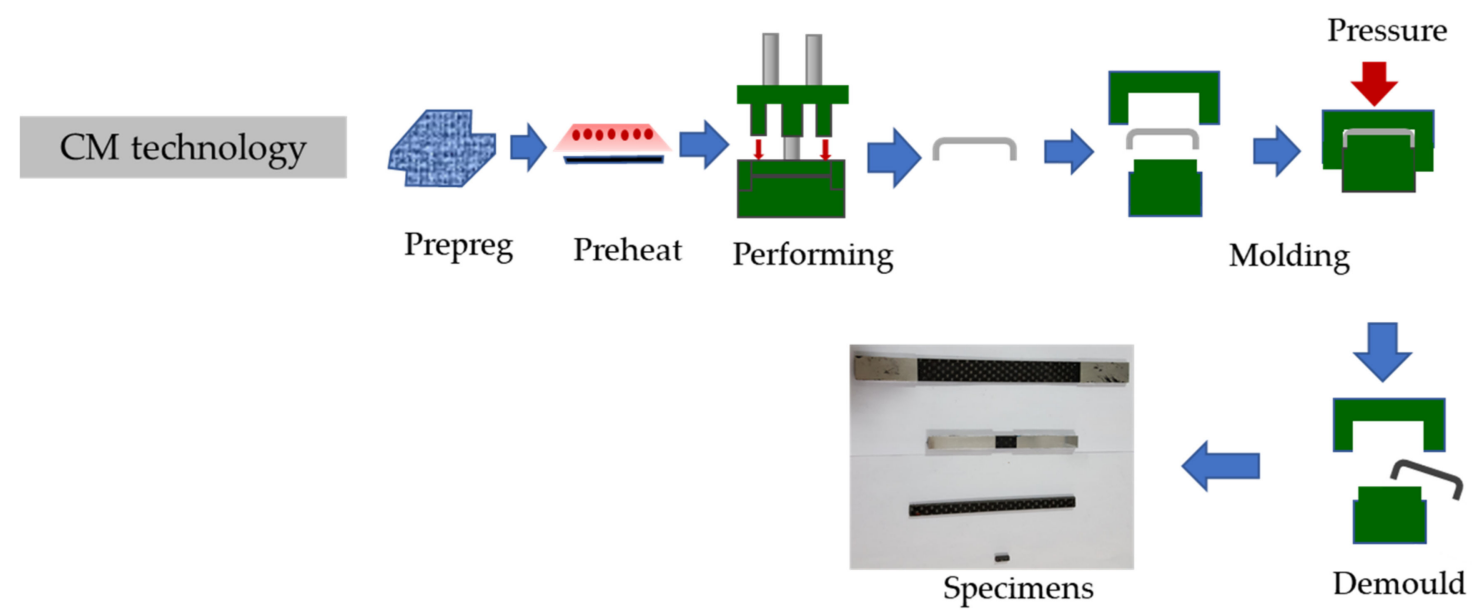

Scheme 1. Flow chart of compression molding (CM) technology.

\subsection{Preparation of Composite Samples by RTM}

A certain number of layers of plain CF dry clothes were gradually laid in the mold and the mold was closed. The RTM equipment was turned on and RTM was performed with specific RTM parameters. The sprue gate valve was closed when the resin system filled the cavity. The exhaust port valve was closed when little bubbles appeared in the discharged resin system from one end of the exhaust port. Then, the composite was cured in an oven under specific conditions and ejected from the mold after cooling. The RTM scheme is shown in Scheme 2.

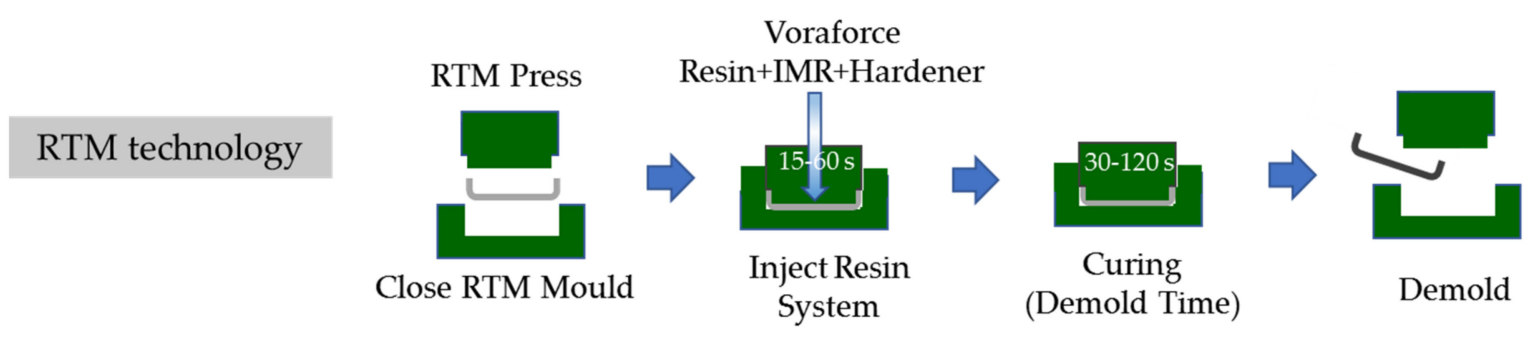

Scheme 2. Flow chart of resign transfer molding (RTM) technology. 


\subsection{Preparation of Composite Samples by CRTM}

A certain number of layers of plain CF dry clothes were gradually laid in the mold and the mold closure was controlled to ensure high permeability. The resin was injected according to specific parameters in vacuum. The sprue gate valve was closed when the resin system filled the cavity. The exhaust port valve was closed when little bubbles appeared in the discharged resin system from one end of the exhaust port. The mold was closed to a certain degree to improve the resin content and impregnation. A certain pressure was applied under heating to discharge residual bubbles. The composite was heated to the curing temperature to improve the compactness of the materials under certain pressure according to the CM technology. The composite was ejected from the mold after cooling. The CRTM scheme is shown in Scheme 3.

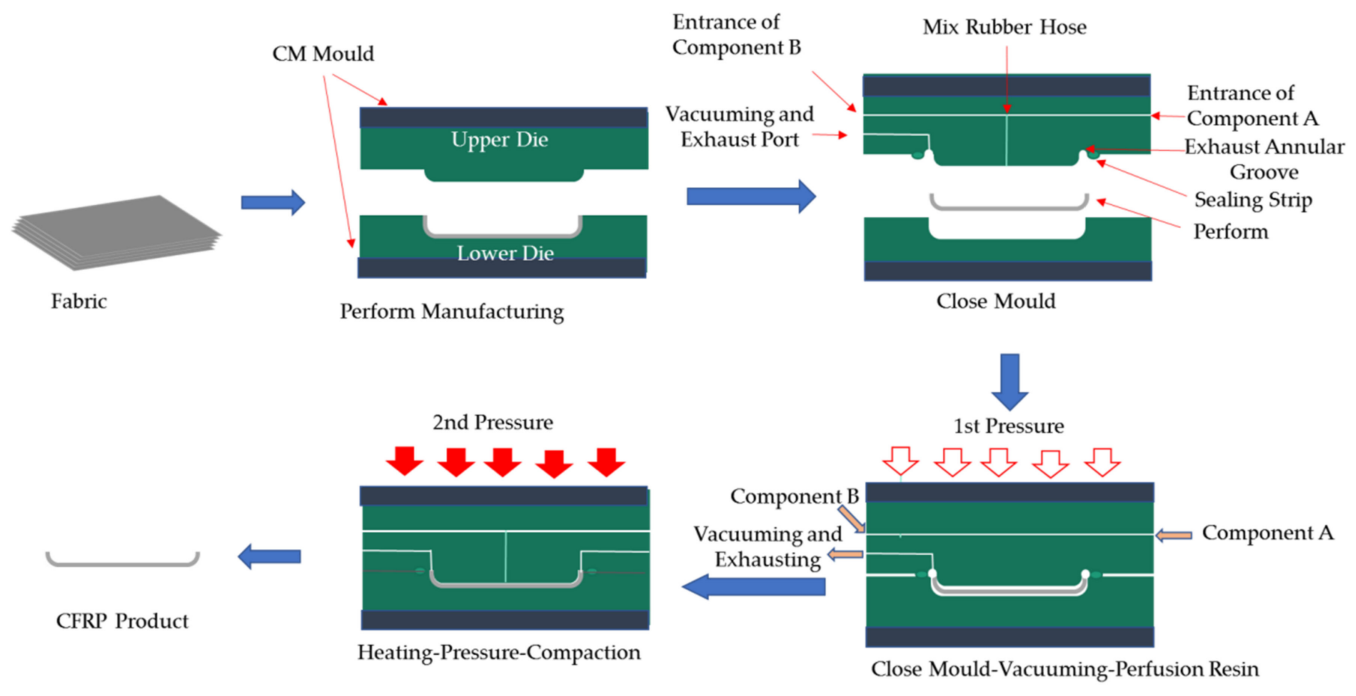

Scheme 3. Flow chart of compression-resin transfer molding (CRTM) technology.

\section{Results and Discussions}

\subsection{Properties of Epoxy Resin System}

\subsubsection{Thermal Properties of Epoxy Resin System}

Composite materials should withstand elevated temperatures to maintain structural integrity. If the service temperature exceeds the glass transition temperature $\left(\mathrm{T}_{\mathrm{g}}\right)$, the polymer matrices will rapidly lose their strength and stiffness, which in turn will weaken the fiber-matrix interfacial bonding strength $[10,25]$. As a result, the mechanical properties may drastically deteriorate at elevated temperatures, leading to a breakdown in structural integrity. To maintain structural integrity, it is critical to investigate the thermal characteristics of the epoxy resin in the molded CF-reinforced composites.

The differential scanning calorimetry curves of the resin system at different heating rates are displayed in Figure 2. During the curing reaction, the initial temperature $\left(T_{i}\right)$, peak temperature $\left(T_{p}\right)$, and finial temperature $\left(T_{f}\right)$ increased as heating rate increased, as summarized in Table 1.

Table 1. Characteristic temperatures of the resin system.

\begin{tabular}{cccc}
\hline Heating Rate $\left({ }^{\circ} \mathbf{C} / \mathbf{m i n}\right)$ & $\mathbf{T}_{\mathbf{i}}\left({ }^{\circ} \mathbf{C}\right)$ & $\mathbf{T}_{\mathbf{p}}\left({ }^{\circ} \mathbf{C}\right)$ & $\mathbf{T}_{\mathbf{f}}\left({ }^{\circ} \mathbf{C}\right)$ \\
\hline 2 & 64 & 94 & 133 \\
5 & 68 & 106 & 153 \\
7 & 71 & 114 & 165 \\
10 & 74 & 126 & 184 \\
0 & 62 & 86 & 121 \\
\hline
\end{tabular}




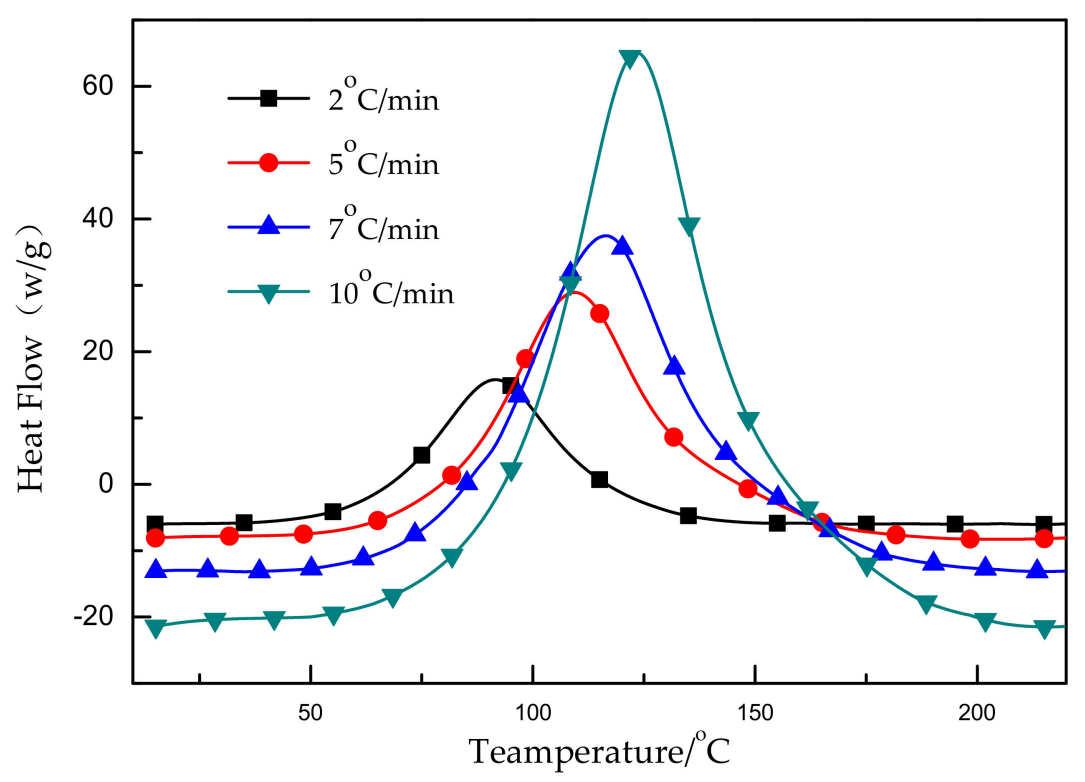

Figure 2. Differential scanning calorimetry (DSC) curves of the resin system.

Based on the characteristic temperatures at different heating rates listed in Table 1, the characteristic temperatures at a heating rate of $0{ }^{\circ} \mathrm{C} / \mathrm{min}$ were calculated by the extrapolation method. As shown in Figure 3, the $Y$-intercept values are the characteristic temperature values including $T_{i}, T_{p}$ and $\mathrm{T}_{\mathrm{f}}$, which are $62{ }^{\circ} \mathrm{C}, 86^{\circ} \mathrm{C}$, and $121^{\circ} \mathrm{C}$, respectively. It could be concluded that the crosslinking temperature was about $90^{\circ} \mathrm{C}$ and the curing temperature was around $120^{\circ} \mathrm{C}$.

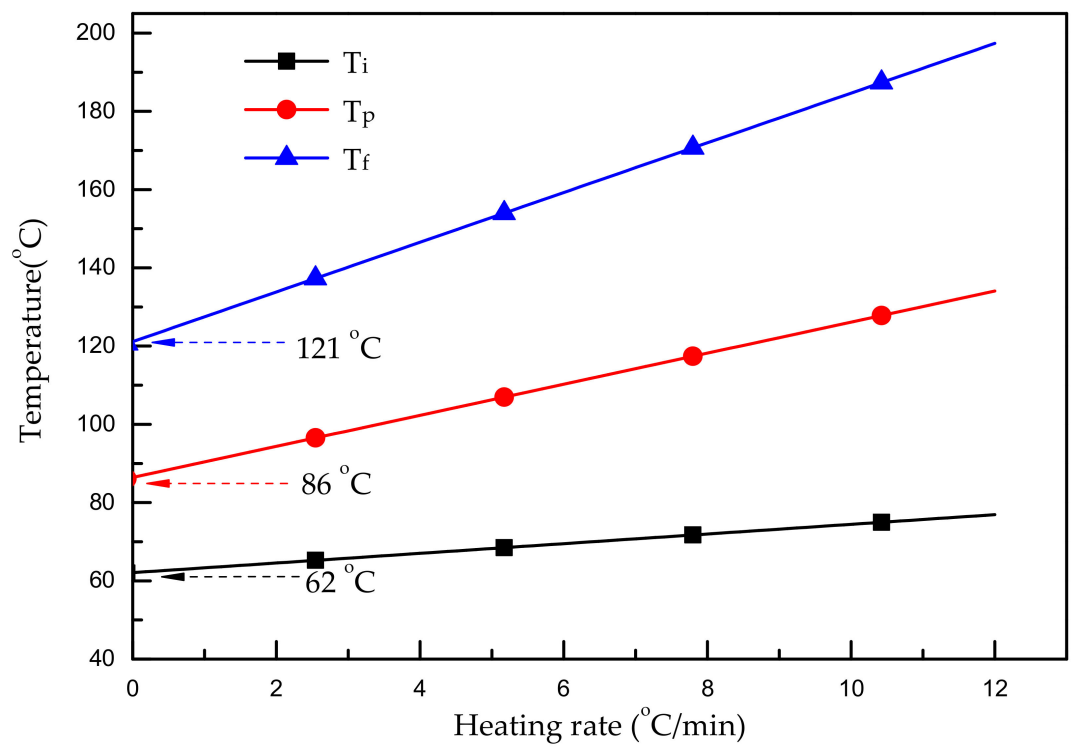

Figure 3. Extrapolation method to determine curing temperature of the resin system.

The characteristic temperatures of the X4302A/B resin system were calculated by the extrapolation method from the DSC curves of the resin system, which were obtained by the DSC measurement. As shown in Figure 4, at characteristic temperatures of $62{ }^{\circ} \mathrm{C}, 86^{\circ} \mathrm{C}$ and $121{ }^{\circ} \mathrm{C}$, the heat release time under a constant temperature was $90 \mathrm{~min}, 30 \mathrm{~min}$, and $20 \mathrm{~min}$, respectively. Theoretically, the post-curing temperature and time, play important roles in the curing stage of the resin system. A proper extension of time contributed to an improved crosslinking degree, which could improve the mechanical properties to some extent. The experiment confirmed that the curing conditions of $\mathrm{X} 4302 \mathrm{~A} / \mathrm{B}$ resin was set as $90^{\circ} \mathrm{C} / 30 \mathrm{~min}+120^{\circ} \mathrm{C} / 60 \mathrm{~min}$. 


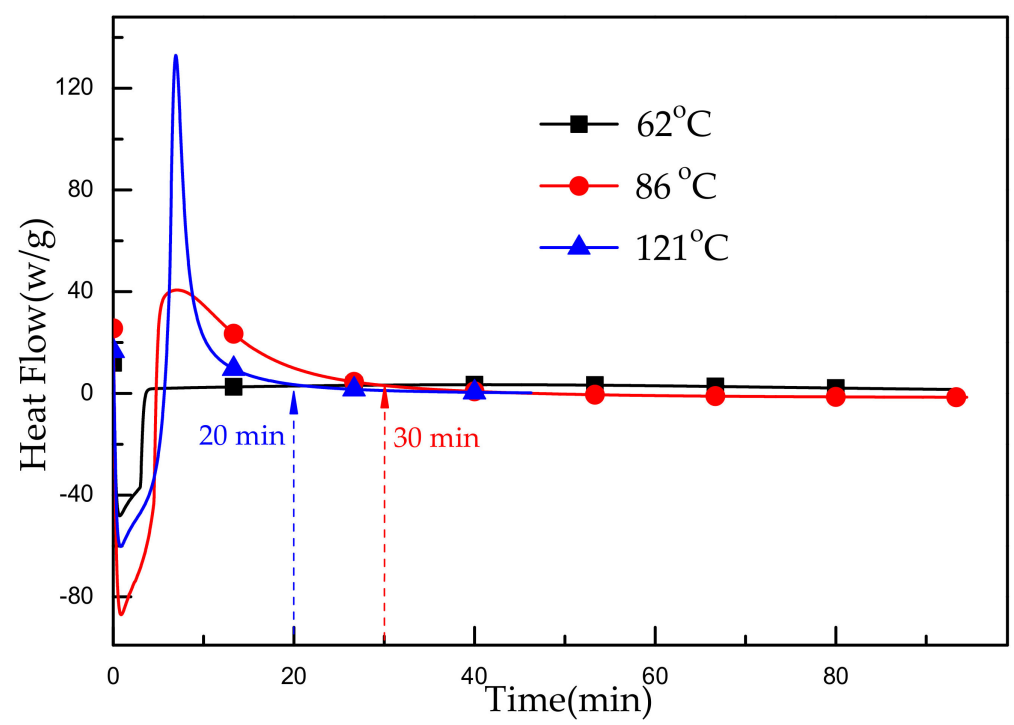

Figure 4. Isothermal DSC curves of the resin systems.

\subsubsection{Rheological Properties of Epoxy Resin System}

The rheological properties of the epoxy resin system include viscosity and elasticity. To achieve complete impregnation, a lower viscosity of the resin before the gel point is essential. Ordinally, the viscosity value of RTM technology should be below $600 \mathrm{mPa} \cdot \mathrm{s}$. Owing to the insignificant influence of shear rate on the rheological properties before the gel point [26], the change in resin viscosity is mainly associated with an increase in temperature. As shown in Figure 5, the viscosity of the resin system decreased slowly and then increased sharply with increasing temperature. From $40{ }^{\circ} \mathrm{C}$ to $90{ }^{\circ} \mathrm{C}$, the viscosity values met the requirements of RTM. A low-viscosity platform appeared around $85^{\circ} \mathrm{C}$ and reached the minimum value, which contributed to good impregnation of the CFs by the resin system. Furthermore, the resin system began to cure at $60^{\circ} \mathrm{C}$, as shown in Figure 4 , and the viscosity of the resin below $40{ }^{\circ} \mathrm{C}$ reached $287 \mathrm{mPa} \cdot \mathrm{s}$, which satisfied the viscosity requirement of molding. Therefore, $40{ }^{\circ} \mathrm{C}$ was chosen as the optimal injection temperature.

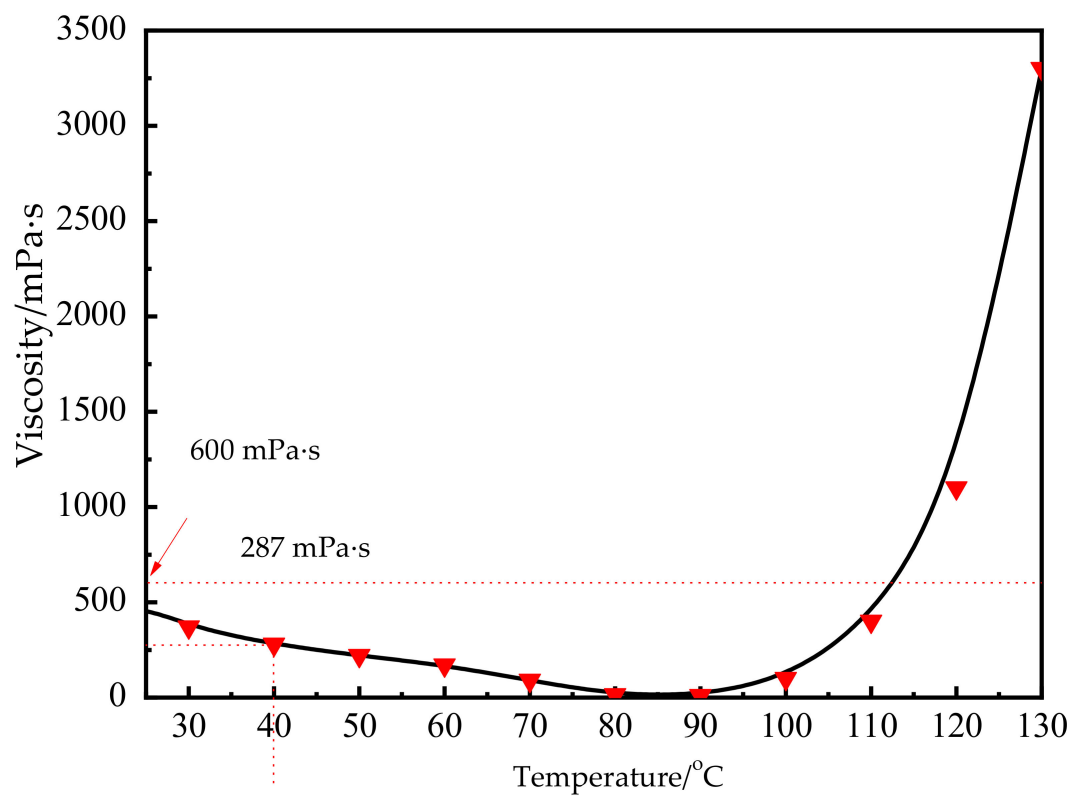

Figure 5. Viscosity variations of $\mathrm{X} 4302 \mathrm{~A} / \mathrm{B}$ resin system with temperature. 
Mechanical properties of the resin casting body performed on the universal testing machine were listed in Table 2. The high strength and modulus lay the foundation for the carbon fiber reinforced composites.

Table 2. Mechanical properties of resin casting body.

\begin{tabular}{ccccccccc}
\hline $\begin{array}{c}\text { Tensile } \\
\text { Strength } \\
/ \mathbf{M P a}\end{array}$ & $\begin{array}{c}\mathrm{CV} \\
\mathbf{I} \%\end{array}$ & $\begin{array}{c}\text { Tensile } \\
\text { Modulus } \\
/ \mathrm{GPa}\end{array}$ & $\begin{array}{c}\text { Elongation } \\
/ \%\end{array}$ & $\begin{array}{c}\text { Bending } \\
\text { Strength } \\
/ \mathbf{M P a}\end{array}$ & $\begin{array}{c}\mathrm{CV} \\
\mathbf{l} \%\end{array}$ & $\begin{array}{c}\text { Bending } \\
\text { Modulus } \\
/ \mathrm{GPa}\end{array}$ & $\begin{array}{c}\text { Impact } \\
\text { Strength/ } \\
\mathbf{K J} / \mathbf{m}^{2}\end{array}$ & $\begin{array}{c}\mathbf{C V} \\
/ \%\end{array}$ \\
\hline 768.56 & 3.46 & 3.01 & 4.02 & 767.64 & 2.82 & 3.07 & 16.87 & 4.66 \\
\hline
\end{tabular}

\subsection{Mechanical Properties of Composite Prepared by CM}

To compare the mechanical properties of the composites prepared by CM, RTM, and CRTM, a common prepreg was used for CM (fabric /T700-12k, resin/YPH-42T) and shows excellent properties, while a dry CF cloth was used for RTM and CRTM.

The pressure duration played an important role in the molding process. It could accelerate the impregnation of the CFs by the resin during the low-viscosity stage of the resins, which is beneficial to the exclusion of bubbles present between the filaments and the combination of resin with the reinforcement. Herein, the subsection heating plan shown in Figure 6 was set as the optimal heating and pressing solution.

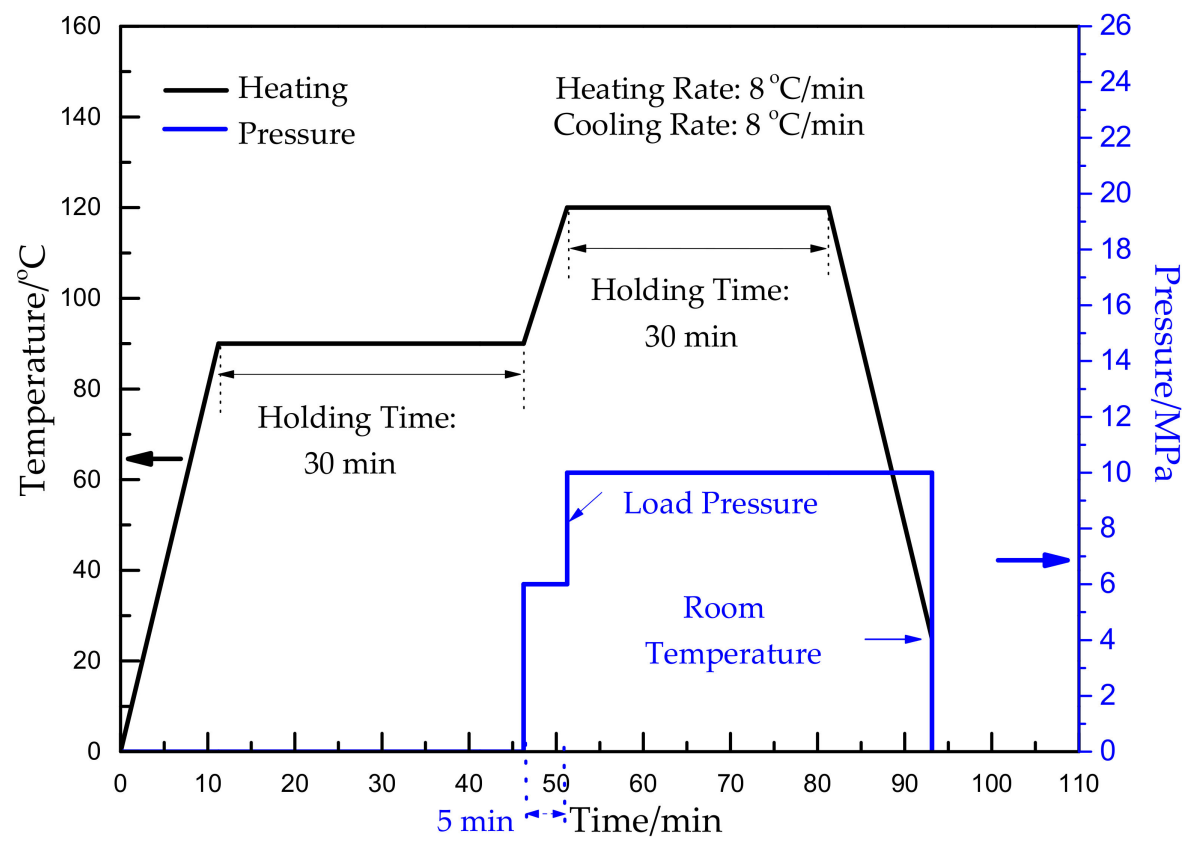

Figure 6. Subsection heating and pressurization schemes of the molding process.

A composite sample molded by the CM method is shown in Figure 7. The sample shows a smooth surface without any blowholes, which verified the feasibility of the heating and pressure plan.

The measured mechanical properties and CV (coefficient of variance) values of the composite samples are displayed in Table 3.

Table 3. Mechanical properties of composite sample molded by compression molding (CM).

\begin{tabular}{cccccccc}
\hline $\begin{array}{c}\text { Tensile } \\
\text { Strength } \\
/ \mathbf{M P a}\end{array}$ & $\begin{array}{c}\mathrm{CV} \\
/ \%\end{array}$ & $\begin{array}{c}\text { Bending } \\
\text { Strength } \\
/ \mathbf{M P a}\end{array}$ & $\begin{array}{c}\mathrm{CV} \\
/ \%\end{array}$ & $\begin{array}{c}\text { Compressive } \\
\text { Strength } \\
/ \mathbf{M P a}\end{array}$ & $\begin{array}{c}\mathrm{CV} \\
/ \%\end{array}$ & $\begin{array}{c}\text { Interlaminar } \\
\text { Shear Strength } \\
/ \mathrm{MPa}\end{array}$ & $\begin{array}{c}\mathrm{CV} \\
/ \%\end{array}$ \\
\hline 768.56 & 2.82 & 767.64 & 3.86 & 417.59 & 4.48 & 286.90 & 4.22 \\
\hline
\end{tabular}




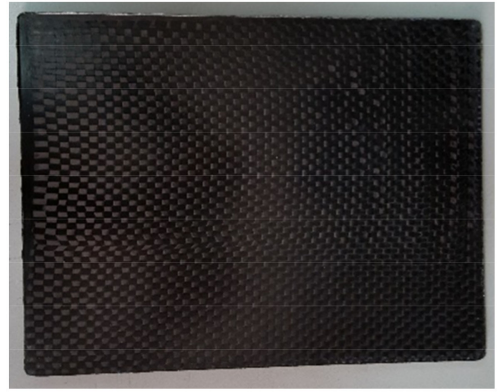

(a)

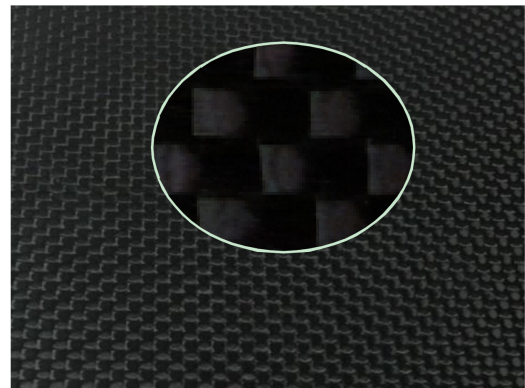

(b)

Figure 7. Specimen's photo (a) and surface morphology contrast (b) of the composites prepared by CM process.

\subsection{Mechanical Properties of Composite Samples Prepared by RTM}

During the RTM process, a dry carbon cloth was used as the CF source. After $30 \mathrm{~min}$ of vacuuming, the bisphenol A-type epoxy resin and amine curing agent were poured from a resin tank and curing agent tank, respectively, and mixed at the injection port to inject into the mold at a certain injection rate. Thus, the resin temperature, infusion speed, injection pressure, and positions and numbers of sprue gate and exhaust port play important roles in composite preparation. Based on the thermodynamic and rheological analyses of resin combined with experimental results, the parameters of the RTM process are listed in Table 4.

Table 4. Parameters of resign transfer molding (RTM) process.

\begin{tabular}{ccc}
\hline Injection Rate/cc $\cdot \mathbf{m i n}^{\mathbf{- 1}}$ & Injection Pressure/MPa & Temperature ${ }^{\circ} \mathbf{C}$ \\
\hline 40 & 0.15 & 40 \\
\hline
\end{tabular}

As shown in Figure 8, the composite sample appears much smoother with no dry spot or blowhole. The mechanical properties and CV (coefficient of variance) values of the composite samples are summarized in Table 5 .

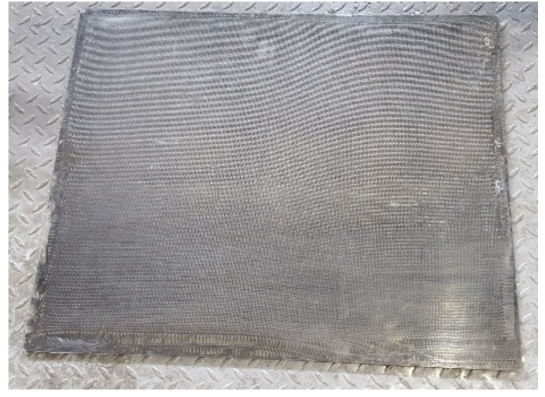

(a)

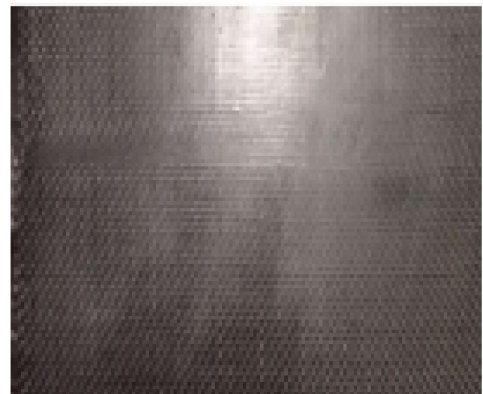

(b)

Figure 8. Specimen's photo (a) and appearance of template (b) prepared by RTM process.

Table 5. Mechanical properties of samples under different conditions.

\begin{tabular}{cccccccc}
\hline $\begin{array}{c}\text { Tensile } \\
\begin{array}{c}\text { Strength } \\
\text { /MPa }\end{array}\end{array}$ & $\begin{array}{c}\mathrm{CV} \\
/ \%\end{array}$ & $\begin{array}{c}\text { Bending } \\
\text { Strength } \\
/ \mathbf{M P a}\end{array}$ & $\begin{array}{c}\mathrm{CV} \\
/ \%\end{array}$ & $\begin{array}{c}\text { Compressive } \\
\text { Strength } \\
/ \mathbf{M P a}\end{array}$ & $\begin{array}{l}\mathrm{CV} \\
/ \%\end{array}$ & $\begin{array}{c}\text { Interlaminar } \\
\text { Shear Strength } \\
/ \mathbf{M P a}\end{array}$ & $\begin{array}{c}\mathrm{CV} \\
/ \%\end{array}$ \\
\hline 571.69 & 3.24 & 553.59 & 4.32 & 335.46 & 3.66 & 179.05 & 2.98 \\
\hline
\end{tabular}




\subsection{Preparation and Mechanical Properties of Composite Samples Prepared by CRTM}

By investigating the optimum parameters of CM and RTM, we obtained the optimum parameters of CRTM. Firstly, during the injection stage, the injection pressure was set as $0.15 \mathrm{MPa}$ at a rate of $40 \mathrm{cc} / \mathrm{min}$ under $40^{\circ} \mathrm{C}$. Secondly, during the curing stage of $\mathrm{CM}$, the sample was heated up to $90^{\circ} \mathrm{C}$ under no pressure and held for $30 \mathrm{~min}$. Thirdly, a pressure of $6 \mathrm{MPa}$ was applied for $5 \mathrm{~min}$ to discharge the excess resin and bubbles in the mold cavity. Finally, load pressure and an additional load pressure of $10 \mathrm{MPa}$ was applied with heating up to $120^{\circ} \mathrm{C}$ for $60 \mathrm{~min}$. The subsection heating and pressure plan is shown in Figure 9.

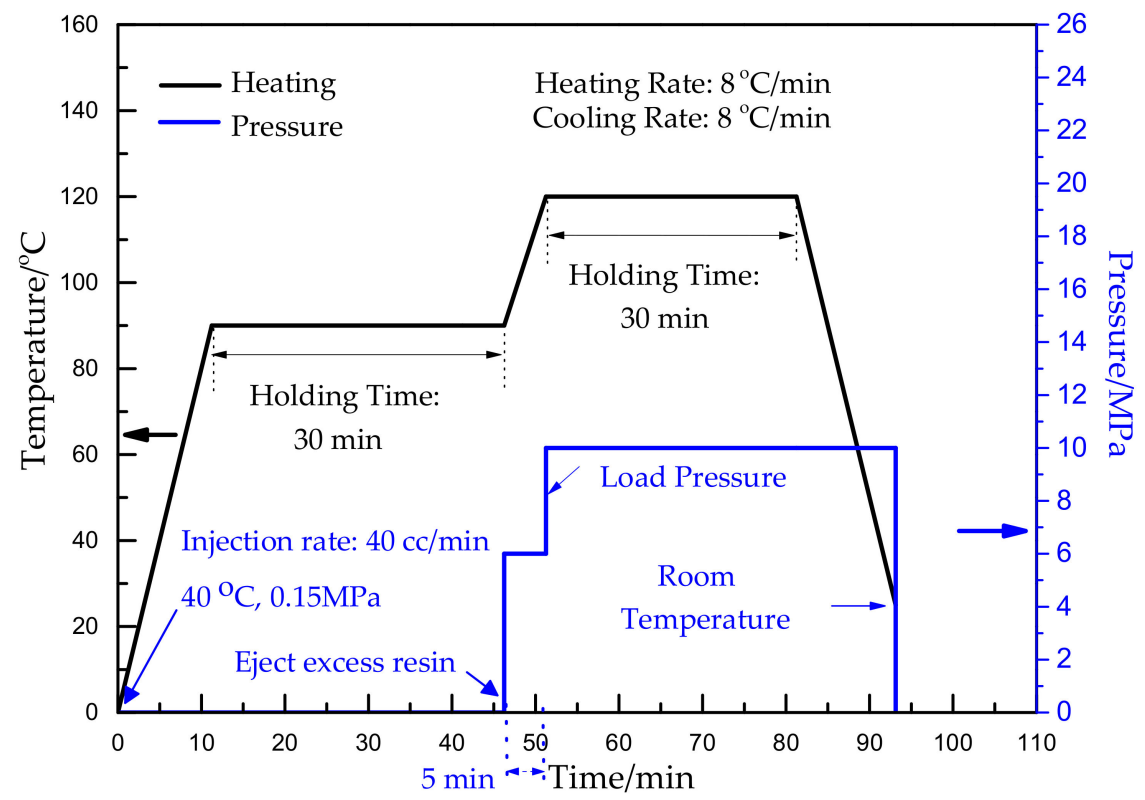

Figure 9. Subsection heating and pressurization schemes of the molding process.

The mechanical properties and CV values of the composite samples prepared by CRTM are listed in Table 6. The mechanical properties of the samples prepared by CRTM are superior to those of the samples prepared by CM and RTM, as shown in Figure 10. The tensile strength, bending strength, compressive strength, and interlaminar shear strength improved by $42.9 \%, 41.2 \%, 21.5 \%$, and $77.3 \%$, respectively, compared with those of the samples prepared by RTM.

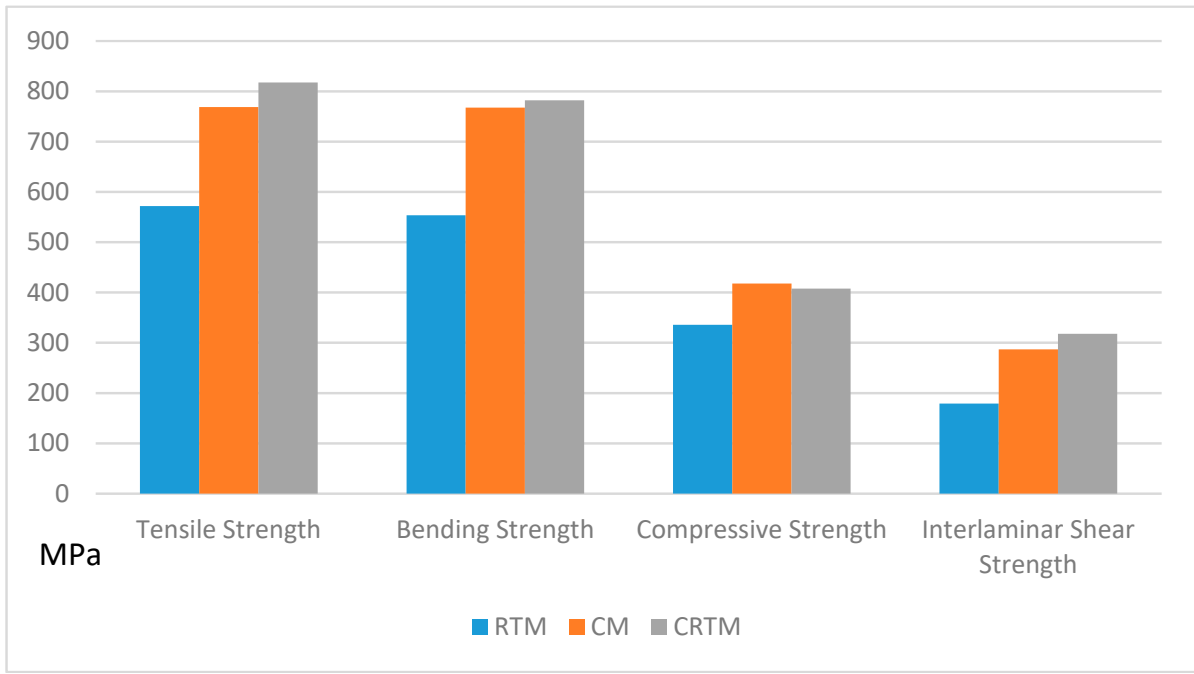

Figure 10. Mechanical properties of samples prepared by CM, RTM, and CRTM. 
Table 6. Mechanical properties of composite samples prepared by compression resin transfer molding (CRTM).

\begin{tabular}{cccccccc}
\hline $\begin{array}{c}\text { Tensile } \\
\text { Strength } \\
/ \mathrm{MPa}\end{array}$ & $\begin{array}{c}\mathrm{CV} \\
/ \%\end{array}$ & $\begin{array}{c}\text { Bending } \\
\text { Strength } \\
/ \mathrm{MPa}\end{array}$ & $\begin{array}{c}\mathrm{CV} \\
/ \%\end{array}$ & $\begin{array}{c}\text { Compressive } \\
\text { Strength } \\
/ \mathbf{M P a}\end{array}$ & $\begin{array}{l}\mathrm{CV} \\
/ \%\end{array}$ & $\begin{array}{c}\text { Interlaminar } \\
\text { Shear Strength } \\
/ \mathrm{MPa}\end{array}$ & $\begin{array}{c}\mathrm{CV} \\
/ \%\end{array}$ \\
\hline 817.51 & 3.67 & 781.90 & 4.05 & 407.54 & 4.12 & 317.53 & 3.89 \\
\hline
\end{tabular}

Metallurgical microscopy photos of the composite samples prepared by the three molding methods are shown in Figure 11. Here, images I, II, and III represent the fiber equatorial plane section and images I', II', and III' represent the fiber axial section of the composites prepared by CRTM, $\mathrm{CM}$, and RTM, respectively. In the equatorial plane section of I (CRTM) and II (CM), the CFs are distributed uniformly in the resin, while a resin-enriched area is seen in III (RTM). In the fiber axial section images, the inter-layer fibers appear more aligned and compact and the inter-layer resin system content is minimal.
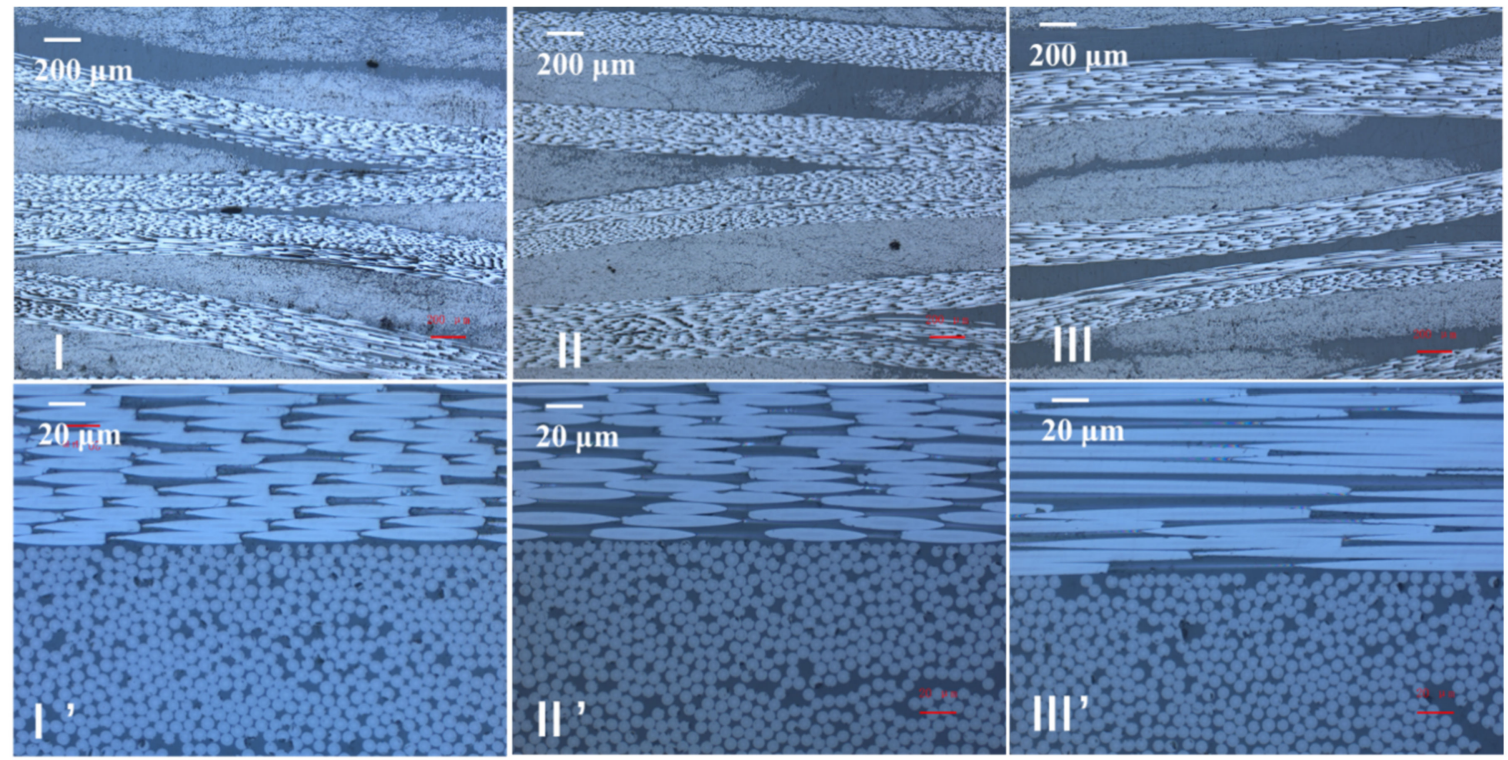

Figure 11. Microstructure of composite samples prepared by different molding methods: (I, II, and III) fiber equatorial plane section (scale: $200 \mu \mathrm{m}$ ) and ( $\mathrm{I}^{\prime}, \mathrm{II}^{\prime}$, and III') fiber axial section (scale: $\left.20 \mu \mathrm{m}\right)$ of composites prepared by CRTM, CM, and RTM, respectively.

The volume fraction and porosity of the composites are summarized in Table 7 . The volume fraction of the composite prepared by CRTM improved by $5.3 \%$ and the porosity decreased by $45.2 \%$ compared with those of the composite prepared by the RTM process; this demonstrates the optimal processing conditions of CRTM.

Table 7. Volume fraction and porosity of composite samples prepared by CRTM, RTM, and CM.

\begin{tabular}{ccc}
\hline Processing Style & Volume Fraction/\% & Porosity/\% \\
\hline CRTM & 78.1 & 0.23 \\
CM & 78.5 & 0.26 \\
RTM & 74.2 & 0.42 \\
\hline
\end{tabular}

\section{Conclusions}

In this study, carbon fiber-reinforced epoxy composites with high-performance were prepared by CRTM technology. Light-spots of CRTM technology were concluded as, 
(1) the molding parameters of CRTM technology was confirmed by investigation on influence factors of CM and RTM technology, including filling temperature, infusion speed, heating and pressure scheme, etc.

(2) the experimental results showed that the composites prepared by CRTM exhibited superior mechanical properties than those of the composites prepared by RTM and CM. The composite prepared by CRTM showed up to $42.9 \%, 41.2 \%, 77.3 \%$, and $5.3 \%$ increases in tensile strength, bending strength, interlaminar shear strength, and volume fraction, respectively, that those of the composites prepared by RTM. Meanwhile, the porosity decreased by $45.2 \%$.

(3) CRTM technology saves cost in molding carbon fiber reinforced composites compared with CM technology, which avoids the problems of storage, transportation, and high cost of prepreg.

In conclusion, the CRTM method has great potential for mass production and could be used for molding structural components of automobiles with high productivity, low cost, and excellent properties.

Author Contributions: Methodology, formal analysis, investigation and writing—original draft preparation, Z.S.; software, validation and writing - review and editing, J.X.; software, S.W.; resources and data curation, L.T. and Y.W.; supervision, H.Z. and S.Z.; project administration and funding acquisition, M.Y.

Funding: This research was funded by the Shanghai Science and Technology Committee (Project No. 17511102801 and 16DZ112140). This research was supported by The Fundamental Research Funds for the Central Universities (Project No. 2232018A3-02) and by Shanghai Automotive Industry Technology Development Foundation of China (Project No. 1715).

Conflicts of Interest: The authors declare no conflicts of interest.

\section{References}

1. Sinmazcelik, T.; Avcu, E.; Bora, M.O.; Coban, O. A review: Fibre metal laminates, background, bonding types and applied test methods. Mater. Des. 2011, 32, 3671-3685. [CrossRef]

2. Zhang, X.H. The state of the art and trend of CF reinforced composites. Fiber Compos. 2004, 1, 50-53.

3. Xiang, L.Y. Progress of manufacturing technology development of advanced polymer matrix composites. Acta Mater. Compos. Sin. 2013, 2,1-9.

4. Chen, X.B. Polymer Matrix Composite Material Manual; Beijing Chemical Industry Press: Beijing, China, 2004; pp. 4-5.

5. Du, S.Y. Advanced composite materials and aerospace engineering. Acta Mater. Compos. Sin. 2007, $24,1-12$.

6. Yi, X.S. Research and Development of Advanced Composites Technology; Defence Industry Press: Beijing, China, 2006; pp. 84-88.

7. Chen, S.J. Composite materials technology and large aircraft. Acta Aeronaut. Astronaut. Sin. 2008, 3, 605-610.

8. Poe, C.C.; Dexter, H.B.; Raju, I.S. Review of the NASA textile composites research. J. Aircr. 1999, 36, 876-884. [CrossRef]

9. Bersuch, L.; Benson, R.; Owens, S. Affordable composite structure for next generation fighters. Materials and Process Affordability-Keys to the Future. In Proceedings of the 43rd International SAMPE Symposium and Exhibition, Anaheim, CA, USA, 31 May-4 June 1998; Kliger, H.S., Rasmussen, B.M., Pilato, L.A., Tolle, T.B., Eds.; pp. 56-65.

10. Lawrence, J.M.; Hsiao, K.T.; Don, R.C.; Simacek, P.; Estrada, G.; Sozer, E.M.; Stadtfeld, H.C.; Advan, S.G. An approach to couple mold design and on-line control to manufacture complex composite parts by resin system transfer molding. Compos. A 2002, 33, 981-990. [CrossRef]

11. Jiang, C.H. RTM Review. Fiber Reinf. Plast./Compos. 1996, 2, 25.

12. Xie, W.Z. RTM process theory and characteristics. Fiber Reinf. Plast./Compos. 2000, 5, 46-48.

13. Sun, B.G. High residual mechanical properties at elevated temperatures of carbon fiber/acetylene-functional benzoxazine composite. Compos. A 2018, 112, 11-17. [CrossRef]

14. Fontana, Q.P.V. Viscosity: Thermal history treatment in resin transfer moulding process modelling. Compos. A 1989, 29, 153-158. [CrossRef]

15. Liu, J.G. Research and development of high-performance epoxy molding compounds. Fine Spec. Chem. 2005, 13, 8-15. 
16. Su, H. Research progress of fiber reinforced epoxy resin composites. Thermosetting Resin 2011, 26, 54-57.

17. Feng, W.; Wang, J.H.; Meng, Z.H. The analysis of voids formation during resin-transfer molding process. J. Wuhan Univ. Technol. 2004, 11, 5-7.

18. Li, B.S.; Wang, Y.G. Research on the mechanism of RTM defect formation. J. Yunnan Univ. 2002, 24, $280-282$.

19. Qin, W. Interface modification of molding compound material. Polym. Mater. Sci. Eng. 2003, 6, $206-208$.

20. Wo, Y.Y. Analysis on the process properties and influence factors of composites molding. Hi-Tech Fiber Appl. 2009, 6, 41-44.

21. Chaudhari, R. Characterization of high-pressure RTM processes for manufacturing of high-performance composites. In Proceedings of the 15th European Conference on Composite Materials, ECCM 2012, Venice, Italy, 24-28 June 2012.

22. Baskarana, M. Manufacturing cost comparison of RTM, HP-RTM and CRTM for an automotive roof. In Proceedings of the 16th European Conference on Composite Materials, ECCM 2014, Seville, Spain, 22-26 June 2014.

23. Bickerton, S.; Kelly, P.A. Compression resin transfer molding (CRTM) in polymer matrix composites. In Manufacturing Techniques for Polymer Matrix Composites (PMCs), 1st ed.; Advani, S., Hsiao, K.-T., Eds.; Woodhead Publishing Limited: Amsterdam, The Netherlands, 2012; pp. 348-380.

24. Keller, A.; Masania, K. Flow and heat transfer during compression resin transfer molding of highly reactive epoxies. Compos. B 2018, 153, 167-175. [CrossRef]

25. Shi, F. Rheological behavior of a bismaleimide resin system for RTM process. Acta Mater. Compos. Sin. 2006, 23, 56-62.

26. Rajesh, K.P. Reinforcement effect of graphene oxide in glass fibre/epoxy composites at in-situ elevated temperature environments: An emphasis on graphene oxide content. Compos. A 2017, 95, 40-53.

(C) 2018 by the authors. Licensee MDPI, Basel, Switzerland. This article is an open access article distributed under the terms and conditions of the Creative Commons Attribution (CC BY) license (http:/ / creativecommons.org/licenses/by/4.0/). 